\title{
Condition Monitoring and Feature Extraction of Stator Current Phasors for Enhanced Fault Diagnosis in AC Drive
}

\author{
Jyothi R, Tejas Holla, Umesh NS, Uma Rao K, Jayapal R
}

\begin{abstract}
AC drives are employed mainly in process plants for various applications. In most industrial applications, Induction motor drives are preferred as they are robust, reliable, and efficient. Process industries have seen a paradigm shift from manual control to automatic control. Advancements in power electronics technology have led to smooth control of the induction motor using variable frequency drives over an entire speed range. Variable Frequency Drives (VFD) comprises of Voltage source inverter and a three phase squirrel cage induction motor. Various electric faults that are incipient in the VFD cause an abrupt change in circuit parameters resulting in insulation damage, reduced efficiency, and leading to catastrophic failure of the entire system. Hence, continuous monitoring of the system parameters such as stator current, speed, and the vibration of the machine is essential to diagnose incipient faults in the system. AI techniques have been effectively used in the fault diagnosis of electrical systems. In the proposed work, simulation results of machine learning-based fault diagnosis techniques are presented. Real-time IoT-based condition monitoring of the Variable Frequency Drive is also implemented for enhanced fault diagnosis of various incipient electrical faults in AC drives. The experimental results obtained are validated with the simulation data.
\end{abstract}

Keywords: Internet of things (IoT), Condition monitoring, Machine Learning, Voltage Source Inverter, Fault Diagnosis

\section{INTRODUCTION}

$\mathrm{M}$ achines are an integral part of the production and processing industries. Amongst all the electrical machines, the induction motor is the most common choice due to its robustness, high reliability, low maintenance, and high efficiency. Electrical machines are controlled by power electronics circuitry. Power electronics devices in modern drive systems are sensitive to different types of faults.

Manuscript received on October 11, 2021.

Revised Manuscript received on October 16, 2021.

Manuscript published on October 30, 2021.

* Correspondence Author

Jyothi R*, Department of Electrical and Electronics Engineering, RV College of Engineering, Bangalore, India. Email: jyothir@rvce.edu.in

Tejas Holla, Department of Electrical and Electronics Engineering, RV College of Engineering, Bangalore, India. Email: tejas.holla@gmail.com

Umesh NS, Department of Electrical and Electronics Engineering, RV College of Engineering, Bangalore, India. Email: umeshns369@gmail.com

Uma Rao K, Department of Electrical and Electronics Engineering, RV College of Engineering, Bangalore, India. Email: umaraok@rvce.edu.in

Jayapal R, Department of Electrical and Electronics Engineering, RV College of Engineering, Bangalore (Karnataka), India

(C) The Authors. Published by Blue Eyes Intelligence Engineering and Sciences Publication (BEIESP). This is an open access article under the CC-BY-NC-ND license http://creativecommons.org/licenses/by-nc-nd/4.0/
Downtime of the power semiconductor switches like diodes, IGBTs in the control circuit affects the productivity of the plant. Some faults may not lead to a complete blackout of the system but can cause huge economic losses [1]. In Voltage Source Inverter (VSI) drive, the probability of incipient faults such as Insulated-Gate Bipolar Transistor (IGBT) failure or diodes open is inevitable. Often the malfunctioning of those devices in the system may go unnoticed by the protection system as their parameters could be within the threshold limits set to operate the relays. Incipient faults may not lead to catastrophe but affect the motor drive and its reliability. Therefore, it is essential to identify the effect of various possible faults and evaluate different parameters of the system, classify and locate the fault in the system to take corrective measures. Most of the research work carried out focused on mechanical faults, mainly rotor bar fault or eccentricity fault of three phase induction motors. For Fault diagnosis in three phase induction motors, MCSA technique was employed. Techniques involved for fault detection were Fast Fourier Transform, ruled based approaches like Fuzzy Logic [2-6], AI techniques like Multilayer Perceptron, Support Vector Machine [7,8], Discrete Wavelet Transform(DWT) [9] were applied for rotor bar fault detection in squirrel cage rotors. Fuzzy logic and DWT techniques involve large computational time. So to improve the computational speed and accuracy of fault detection, cuckoo search, and evolutionary particle swarm optimization techniques were employed. Two-dimensional features, the average current method was used to sense the faults in the system [10-15]. The research carried out is limited to the fault diagnosis in the rotor or to inverter faults classification individually. The proposed work focuses on comprehensive monitoring of the various electrical and mechanical parameters in the system to detect, identify and locate the electrical faults in the variable frequency drive with minimum features using IoT to improve computational capability with precision. The paper is divided into six sections. Introduction to AC drives and the methods available for fault diagnosis are explained in section 1 . The structure of the Variable Frequency Drive and various faults are discussed in section 2. Section 3 includes proposed work, including the simulation model, design, and hardware implementation. Section 4 presents the details about class types, data extraction, and feature selection, and the application of machine learning algorithms. Results, discussion, and conclusion are presented in sections 5 and 6 , respectively. 


\section{Condition Monitoring and Feature Extraction of Stator Current Phasors for Enhanced Fault Diagnosis in AC Drive}

\section{VARIABLE FREQUENCY DRIVE}

Fig. 1 represents the schematic diagram of the variable frequency drive. A diode bridge rectifier is used to obtain dc voltage. The dc link is required to maintain the dc voltage supplied to the inverter. IGBT switches are used in the VSI. Various gating techniques are available to trigger the inverter IGBT switches. With the implementation of SVPWM gating techniques and Third Harmonic Injection Techniques, the stator current harmonics can be reduced within the acceptable limits to maintain the power quality in the system [16].

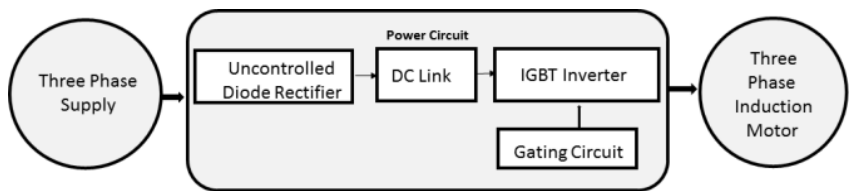

Fig. 1. Schematic Diagram of Variable Frequency Drive

\section{A. Faults in VSI Driven Induction motor}

The faults in the Variable frequency drive can be categorized as electrical and mechanical faults. In electrical faults, both short circuit and open circuit faults can occur in a rectifier and an inverter. Rectifier diode faults can occur due to a short circuit of the diode or by an open circuit of the diode. Upon the occurrence of short circuit faults, corresponding protection circuitry will be activated to mitigate the faults. Open circuit faults in the Rectifier decrease the voltage available at the DC link affecting the performance of the drive even under normal operation of the inverter. Open IGBT faults in the inverter can be termed as an incipient fault in the variable frequency drives as the load will still be running but at reduced efficiency [13]. Cross IGBT open faults are more severe compared to single IGBT open circuit faults as they affect the power quality by increasing harmonics in the system. Faults like SLG, Line-Line, and Lines open faults that are caused at the motor terminal AC power lines due to malfunctioning of Rectifier or inverter circuit will reduce the speed and increase the stator current drawn by the motor load, Short circuit of the lines will damage the motor windings due to the high current flow and in turn, damages the inverter switches and the rectifier switches due to reverse current flow in the system. The Primary protection circuit will operate during the short circuit faults and will reduce the damage caused to the system. Hence the open circuit faults are of major concern in the Variable Frequency Drives.

\section{PROPOSED WORK}

In the proposed work, Methodology followed for implementation of fault detection and classification is as follows:

- Design, simulation, and hardware implementation of variable frequency drives for different electrical open circuit faults are carried out.

- The Parameters such as rectifier output voltage, rectified current, inverter output voltage and stator current phasors and corresponding Total Harmonic
Distortion (THD), and mechanical parameters like speed, vibration are monitored during normal and faulty conditions.

- The essential features for fault detection, classification, and diagnosis are displayed to the operator in real-time through the Thing speak IoT platform, and the selected features are used for training the two supervised machine learning algorithms for accurate fault classification and localization. The results obtained are validated through F1 score.

\section{A. Simulink Diagram}

MATLAB Simulink model of Voltage Source Inverter fed induction motor used for fault creation, and data extraction is as shown in Fig. 2. The circuit was simulated with various gating techniques, namely $180^{\circ}$ conduction mode, Pulse Width Modulation, Sinusoidal Pulse Width Modulation, Third Harmonic Injection Pulse width modulation, and Space Vector Pulse Width Modulation techniques. With the Space Vector Pulse Width Modulation gating technique, the stator current harmonics was reduced to $1 \%$ from $11.27 \%$, as seen in $180^{\circ}$ conduction mode. The simulation consisted of two major data acquisition blocks, namely Measurement subsystem and Stator current Phasor measurement blocks for classification of incipient electrical faults in the system.

The measurement subsystem was used to extract the THD of inverter output voltages, stator currents during different types of faults, and the stator current phasor measurement block was used to measure the phase angle of stator currents. Various electrical open circuit faults in the Rectifier and inverter were created, and the data were extracted for fault diagnosis.

\section{B. Design}

The hardware implementation section involves three phase bridge rectifier with the design of DC link, the IGBT based three phase voltage source inverter including a gate driver circuit, along with the description of measurement unit including sensors for Real-time IoT-based monitoring of AC Drives. The specifications of the hardware set up for condition monitoring, and feature extraction are mentioned in Table 1.In many applications, for a three-phase bridge rectifier, no additional DC-link filter is required as the output ripple voltage is only $4.2 \%$ [4].

A DC link filter is vital for ripple-free operation [7]-[8]. The DC Output Voltage $\left(\mathrm{V}_{\mathrm{o}}\right)$ of the Rectifier is $1.654 * \mathrm{Vm}$, where $\mathrm{Vm}$ is peak Input AC Voltage, which is equal to $538 \mathrm{~V}$. The value of the DC link capacitor is found from Eq. (1).

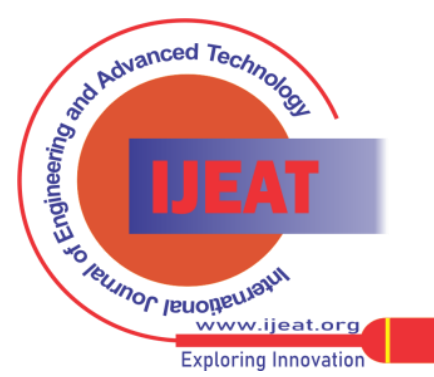




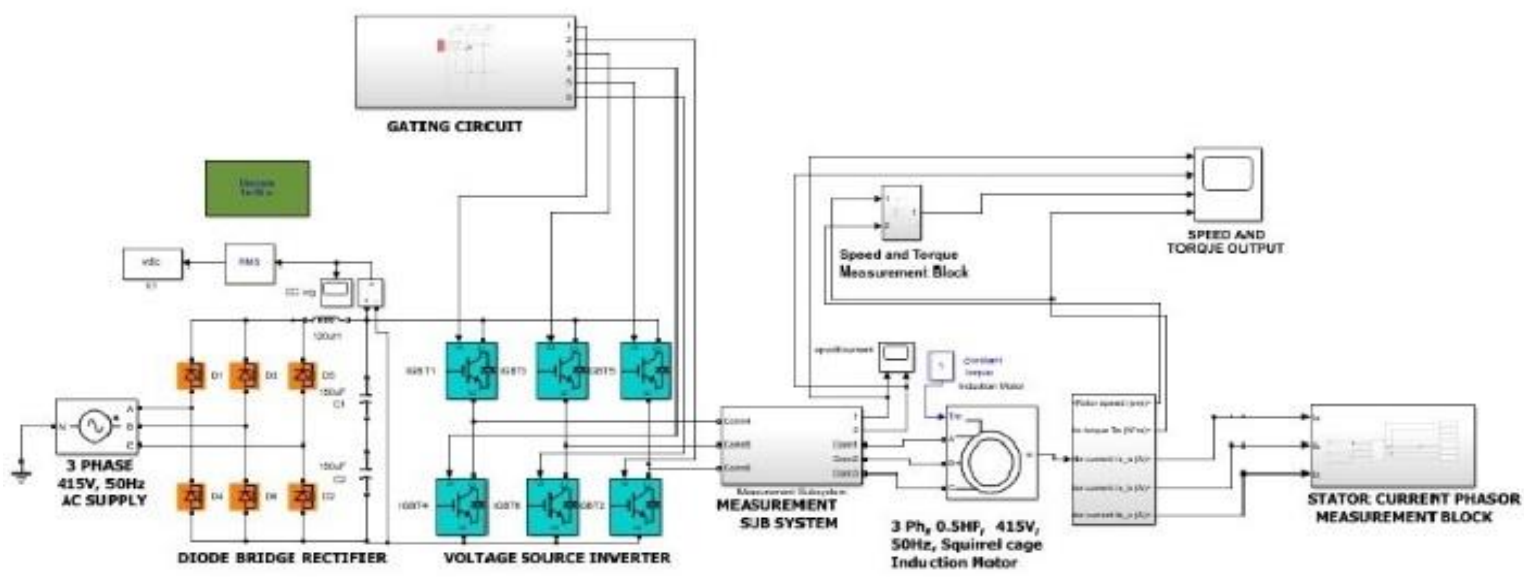

Fig. 2: Simulation model of AC Drive

$$
C=\frac{P_{0}}{2 f V o \Delta V_{r r}}
$$

where $\mathrm{C}$ is the DC link Capacitance, Po is the Average Output power is $806.87 \mathrm{~W}$ (Vdc*Idc), $\mathrm{f}$ is the Frequency of input $50 \mathrm{~Hz}, \mathrm{Vo}$ is the Output DC Voltage $-538 \mathrm{~V}, \Delta \mathrm{Vrr}$ is output ripple Voltage - $10 \%$ of V0. Hence Value of the Capacitor is found to be $117.6 \mu \mathrm{F}$. The value of the DC link inductance is calculated from Eq. (2).

$$
L_{c}=\frac{\mathbb{R}}{3 \pi m\left(m^{2}-1\right) f_{i}}
$$

Where, R - Effective output Resistance $=11.875 \Omega$, fi - Frequency of input $=50 \mathrm{~Hz}, \mathrm{~m}=6$ for three phase bridge inverter, substituting, the value of the inductance is $120 \mu \mathrm{H}$.

\section{Hardware Implementation}

The Power circuit consists of $1200 \mathrm{~V}$, 30Amps rating six power Diodes for implementation of three phase AC to DC converter and $1200 \mathrm{~V}$, 50Amps rating Six IGBTs in the inverter circuit. The ratings of the Power semiconductor are at STP of $25^{\circ} \mathrm{C}$.

Table I: Specifications of Variable Frequency Drive

\begin{tabular}{|c|l|}
\hline Diodes & 30A, 1200V -RHRG30120- 6Nos. \\
\hline DC Link Capacitor & 100uF \\
\hline IGBT & 50A, 1200V -KGT25N120KDA-6 Nos. \\
\hline Microcontrollers & $\begin{array}{l}\text { Arduino Uno, Arduino Mega, Arduino Nano } \\
\text { 1No. each }\end{array}$ \\
\hline Sensors & $\begin{array}{l}\text { Current sensors -ACS716W - 1No. } \\
\text { Temperature sensor-DTH11- 1 No. } \\
\text { Vibration sensor- ADXL335- 1 No. } \\
\text { IR sensor -FC-51-1 No. }\end{array}$ \\
\hline LCD display & 2 Nos. (16 X 2) \\
\hline Wi-Fi module & ESP8266 NodeMCU \\
\hline Motor & $\begin{array}{l}\text { 1 No. 3 phase , 415V, 50Hz, 0.5HP, 1480rpm } \\
\text { squirrel cage Induction motor }\end{array}$ \\
\hline IoT Platform & MATLAB-Thing Speak \\
\hline
\end{tabular}

In the gate driver circuit, the Gate Pulses for $180^{\circ}$ conduction mode are generated by Arduino Mega 2560 microcontroller; these pulses are fed to optocoupler to turn on each IGBT. The optocoupler IC MCT6E is used to isolate the power circuit and gating circuit. $10 \%$ dead band is maintained to prevent the short circuit of the IGBTs of the same leg. Either the inductor value or the capacitance would be high for Low pass filter for elimination of dominant 5th harmonic. Thus, the capacitor draws more current, and there is a huge voltage drop across the inductor. Therefore, it is preferable not to use an LC filter for low rating induction motor. Hence LC passive filter is not implemented as a 0.5HP Induction motor is used.

\section{Measurement Unit}

In the sensor measurement unit, For measurement of stator current, Hall effect sensors are used, and Energy Analyzer (Fluke meter 435 series II) is used to measure Harmonic Components in stator current and voltages. A Digital non-contact type tachometer is developed using an IR module (FC-51) and Arduino Nano microcontroller. Piezo electric-based pre-calibrated vibration sensor (ADXL 335) is used for measuring the abrupt vibration changes in the motor during the occurrence of a fault in the system. Also, the temperature of the induction motor is measured using a thermistor-based DHT 11 sensor. The data extracted is also displayed to the user through the IoT platform and LCD Displays. The Data logged in the IoT platform is used for further analysis and classification of faults in the system. Machine Learning algorithms are applied to the extracted and preprocessed data obtained through sensors deployed to identify the state of the system. The IoT platform used for the condition monitoring of VSI Induction Motor is MATLAB-Thing Speak. Thing Speak is a cloud-based data analytics IoT platform. Code Schedules are allowed to run on the data entering to the specific Thing Speak channel with the MATLAB integration. The data collected is also used to perform actions. IoT-based Hardware Implementation of the proposed work is shown in Fig. 3. Real-time condition monitoring of AC drives using MATLAB-Thing speak platform for fault diagnosis is as shown in Fig. 4(a). Real-time condition monitoring of electrical parameters like stator current phasors and the mechanical parameter like the temperature of AC drives using MATLAB-Thing speak platform for fault diagnosis is as shown in Fig. 4(b). 
Condition Monitoring and Feature Extraction of Stator Current Phasors for Enhanced Fault Diagnosis in AC Drive

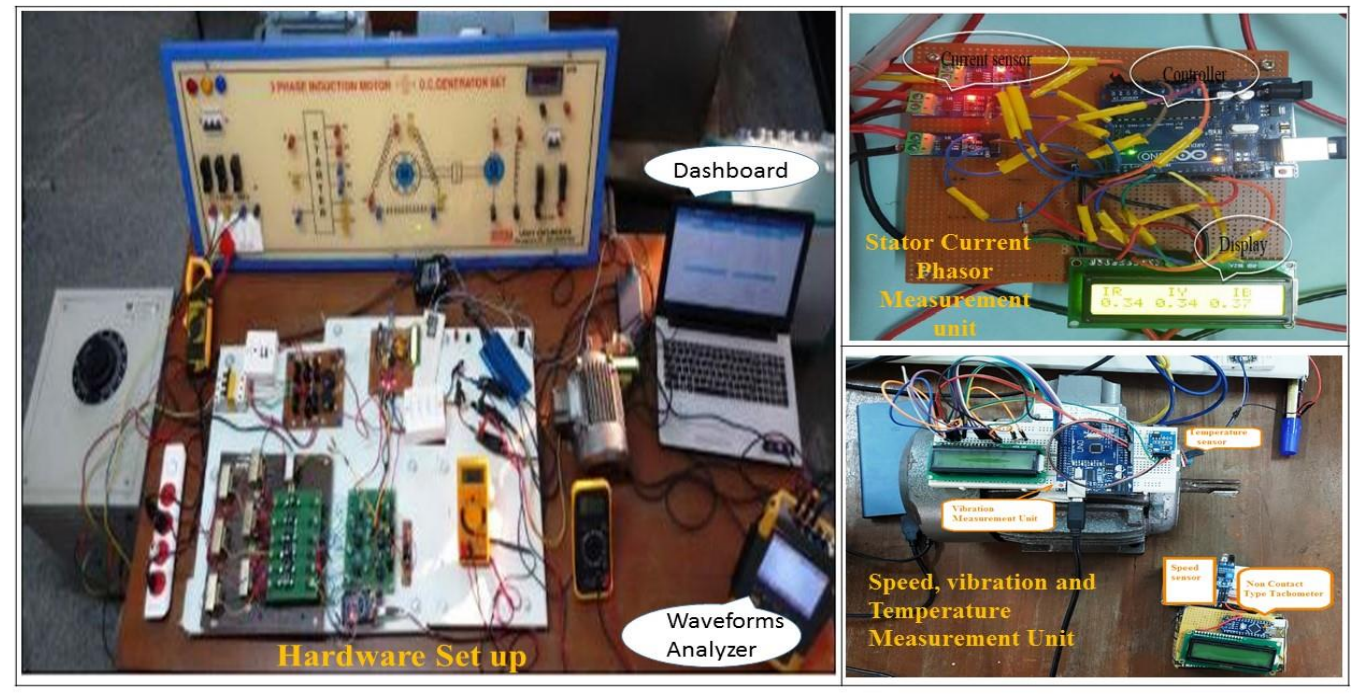

Fig. 3. Hardware Implementation of AC drive with IoT based Measurement and Display unit

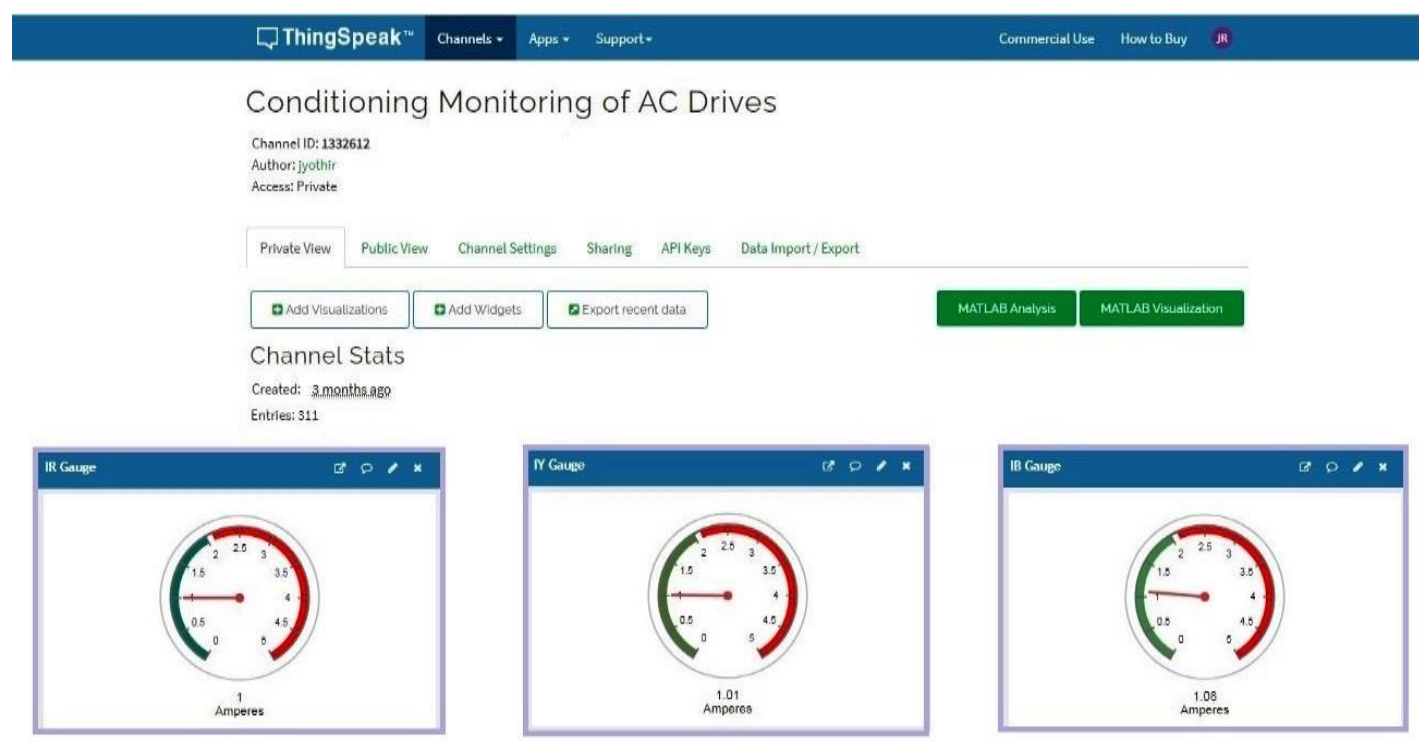

a) Real-time condition monitoring of stator current of AC Drives

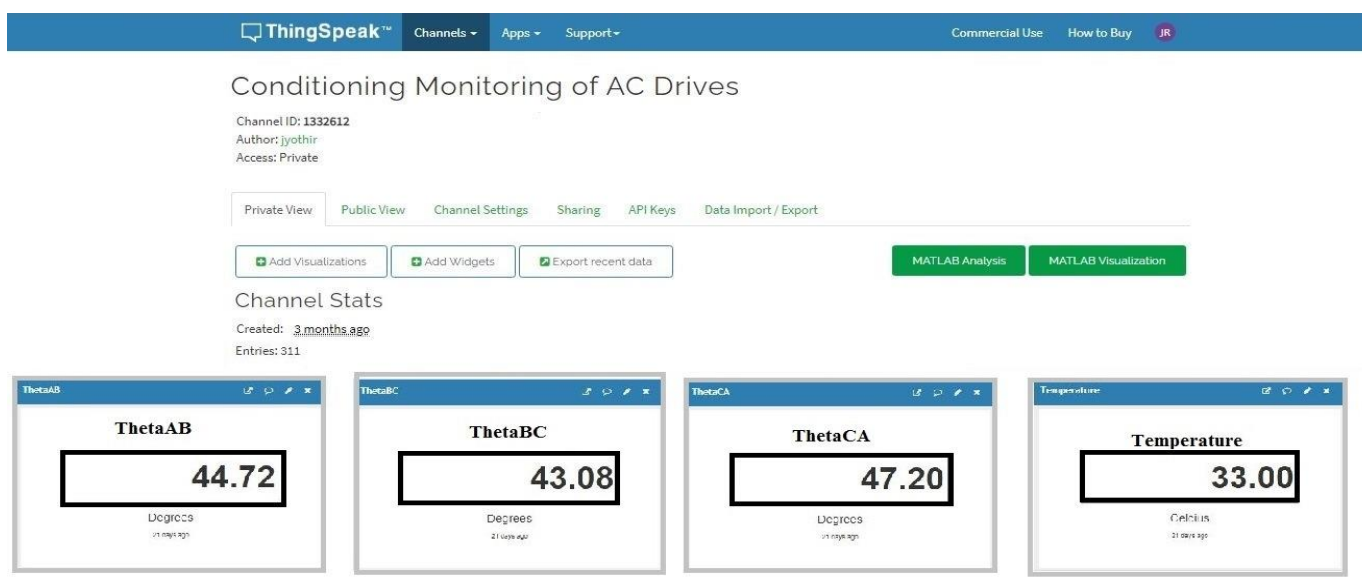

b)Real-time condition monitoring of stator current phasors and temperature of AC Drive

Fig. 4. Real-time condition monitoring of AC Drives using MATLAB-Thing Speak Platform for Fault Diagnosis

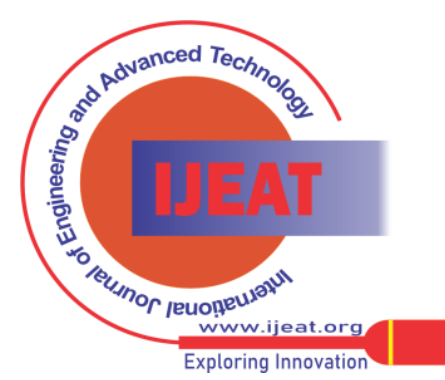




\section{FAULT DIAGNOSIS}

Fault classification and diagnosis is the major task in condition monitoring. Supervised machine learning is the most popularly used fault diagnosis technique. The data extracted from the data acquisition system is preprocessed and the features selected, mainly the stator current and phasors, are trained and tested for both multiclass SVM and MLP-NN algorithms for different kinds of electrical faults in the AC drive system in Google Co-labs Platform.

\section{A. Class Types and Feature Extraction}

Various class Types, including the healthy condition of the variable frequency drive, are considered for simulation and also from the experimentation. The Class Types are labeled as shown in Table 2.

Table II: Class type of the system and label

\begin{tabular}{|c|c|c|c|c|c|c|c|c|c|c|c|c|c|c|c|c|}
\hline \multirow{3}{*}{$\begin{array}{l}\text { Class } \\
\text { Type }\end{array}$} & \multirow{3}{*}{ Healthy } & \multicolumn{3}{|c|}{ Diode Open Fault } & \multicolumn{12}{|c|}{ IGBT Open Fault } \\
\hline & & \multicolumn{2}{|c|}{ Single } & \multirow{2}{*}{$\begin{array}{l}\text { Cross } \\
\text { D1D2 }\end{array}$} & \multicolumn{6}{|c|}{ Single } & \multicolumn{6}{|c|}{ Cross } \\
\hline & & D1 & D2 & & I1 & $\mathrm{I} 2$ & I3 & I4 & I5 & I6 & I1I2 & I3I4 & I5I6 & I6I1 & $\mathrm{I} 2 \mathrm{I} 3$ & I4I5 \\
\hline label & 0 & 1 & 2 & 3 & 4 & 5 & 6 & 7 & 8 & 9 & 10 & 11 & 12 & 13 & 14 & 15 \\
\hline
\end{tabular}

In total, 16 classes are considered, including the health system. Data of output DC voltage, inverter output voltage, Stator currents and their phase angles, total harmonic distortion of output voltage, current, speed, vibration are all extracted from the simulation model and the hardware set up also. However, from the previous investigation, it is observed that the stator current phasors are sufficient for electrical fault detection and classification [18]. Hence only the stator current phasors along with the mechanical parameter like temperature are displayed to the operator in real-time. The simulation data obtained are in validation with the hardware sensors data. Data samples that include the RMS value of three phase stator current and their corresponding phase angles with $\pm 5 \%$ variation in the supply voltage are extracted for training and testing the algorithms from the simulation data set.

\section{RESULTS AND DISCUSSION}

The hardware setup is first tested under the healthy condition at a rated voltage of $415 \mathrm{~V}, 50 \mathrm{~Hz}$ at motor terminals. The output DC voltage of the Rectifier is $540 \mathrm{~V}$ and is in validation with design. The motor is found to be running at a speed of $1480 \mathrm{rpm}$ and draws a 1A rated current from the supply. The waveform obtained from Fluke energy analyzer of inverter output voltages of healthy, single IGBT open fault and cross IGBTs open fault are as shown in Fig. 5, Fig. 6, and Fig. 7. Under the healthy condition, the inverter output voltages and currents are balanced.

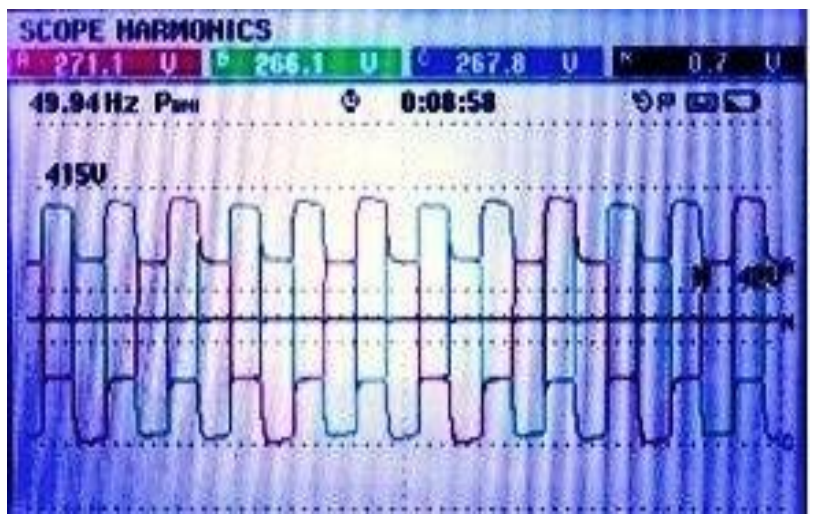

Fig. 5. Line voltage waveform under healthy condition

During a single IGBT open fault, the inverter output voltages and stator currents are distorted, and also a significant change in mechanical parameters such as speed and vibration are recorded.

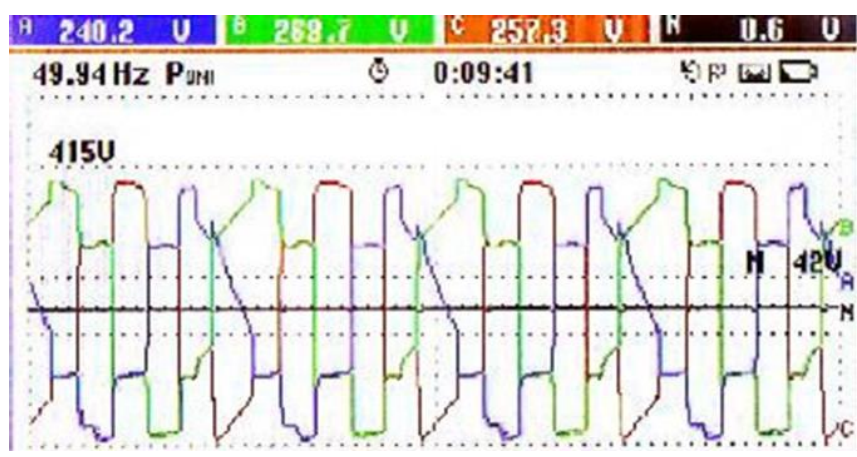

Fig. 6: Distortion in Line Voltage under single IGBT fault

Under the Cross IGBT open fault, there is a significant change in the output voltage as there is distortion in two line voltages along with the speed and vibration parameters.

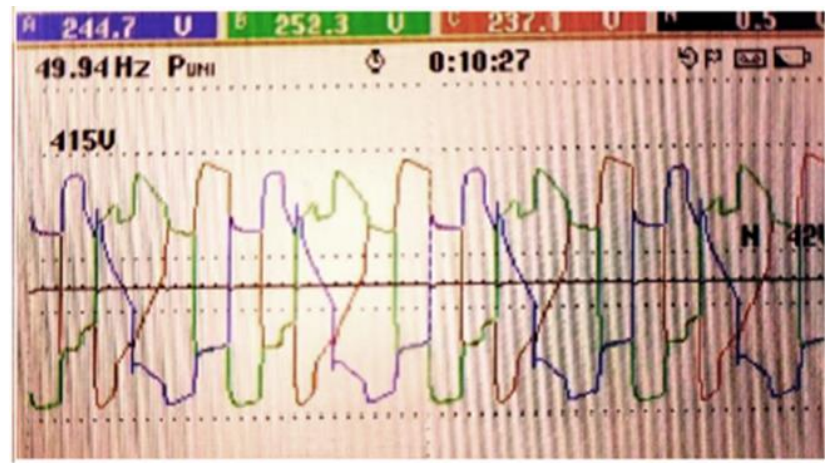

Fig. 7: Distortion in Line Voltage under cross IGBT fault

The data extracted are split into 2027 training and 896 testing data in a 70:30 ratio where stator current phasors are considered as the six features for MLP-NN and Multi-class SVM. The hyperparameters, as shown in Table 3, are used to train fault classification. K-fold cross-validation is included to avoid the overfitting of the model [23]. MLP-NN training with K-fold $(\mathrm{k}=5)$ and testing accuracy are $0.96 \pm 0.05$ and 0.978 , respectively. The confusion matrix of MLP-NN and SVM testing accuracy obtained are as shown in Fig. 8 and Fig. 9. 


\section{Condition Monitoring and Feature Extraction of Stator Current Phasors for Enhanced Fault Diagnosis in AC Drive}

The MLP-NN confusion matrix shows that the healthy and the single diode fault are misclassified. This misclassification does not lead to a severe effect on the system as there are no major observations except a decrease in the rectifier output voltage as per the experimental data. Single IGBT faults and Cross IGBTs faults are classified accurately with the exact location of the fault as shown in confusion matrix.

Table III: Hyperparameters for Fault Diagnosis

\begin{tabular}{|c|c|c|c|c|}
\hline \multicolumn{5}{|c|}{ MLP-NN with K-fold } \\
\hline Activation & Alpha & $\begin{array}{c}\text { Hidden Layer } \\
\text { Sizes }\end{array}$ & $\begin{array}{c}\text { Learning } \\
\text { Rate }\end{array}$ & Solver \\
\hline ReLu & 0.05 & $(50,50,50)$ & adaptive & SGD \\
\hline \multicolumn{5}{|c|}{ Multi Class SVM with K-fold } \\
\hline Features & C & Gamma & Kernel \\
\hline 6 & 0.1 & 1 & RBF \\
\hline
\end{tabular}

Multiclass SVM training with $\mathrm{K}$-fold $(\mathrm{k}=5)$ and the testing accuracy is $0.96 \pm 0.01$ and 0.979 , respectively, with hyperparameters tuned as shown in Table 2. The confusion matrix, as shown in Fig. 9, illustrates that the healthy and the single diode fault and cross diode faults are misclassified. Single IGBT faults and Cross IGBTs faults are classified accurately with the exact location of the fault. As per MLP-NN and Multi-class SVM confusion matrix, the class distribution is uneven. Hence per class F1 score, i.e., the harmonic mean of precision and recall is considered in this proposed work for performance accuracy of fault diagnosis. The Plot of the F1 score for each class type for MLP-NN and Multi-class SVM is shown in the Figure. 10.

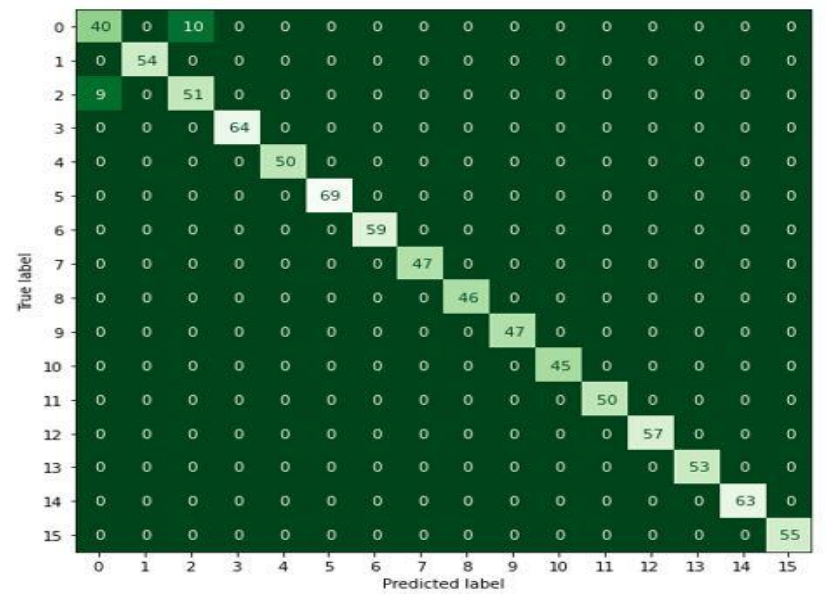

Fig.8: Confusion Matrix of MLP-NN Testing Accuracy

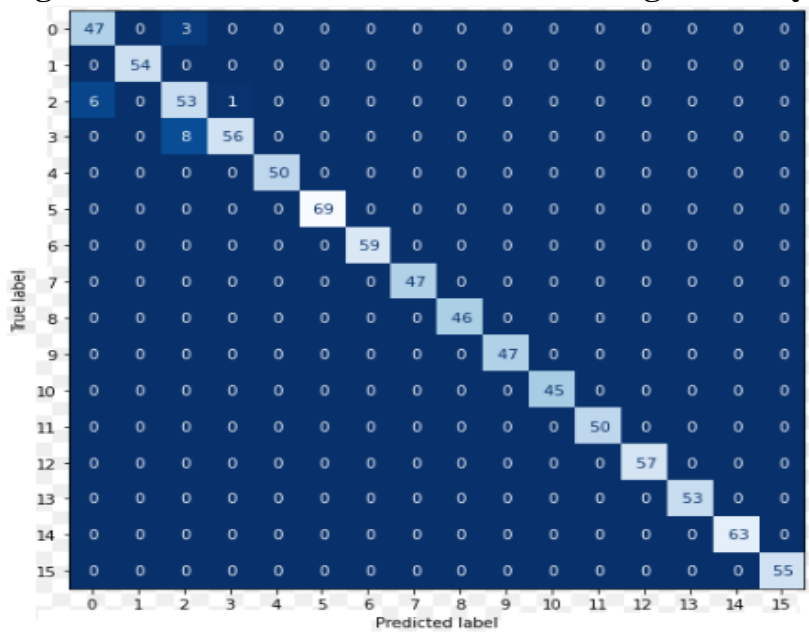

Fig. 9: Confusion Matrix of SVM Testing Accuracy

Retrieval Number: 100.1/ijeat.A31731011121

DOI: 10.35940/ijeat.A3173.1011121

Journal Website: www.ijeat.org

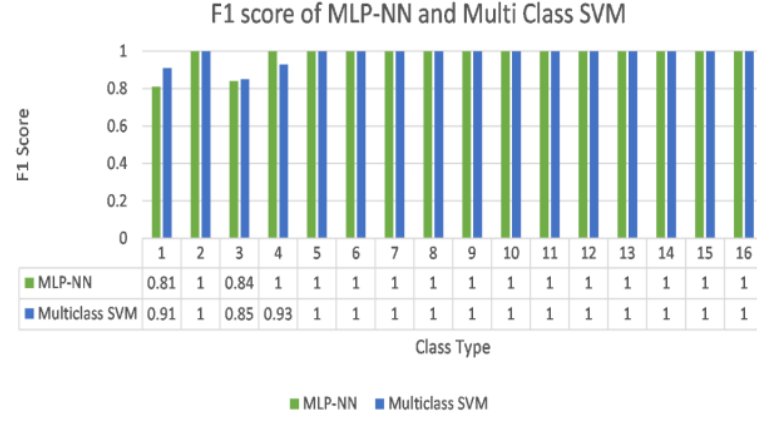

Fig. 10: F1 score of MLP-NN and Multiclass SVM

\section{CONCLUSION}

In this proposed work, the various types of electrical open circuit faults in Variable Frequency drive are considered. The hardware setup of real-time condition monitoring of inverter-driven Induction motor is implemented by creating different types of diode and IGBT open circuit faults in the system. The severity and effect of faults are investigated by monitoring various parameters of the system. From the experimental data, it can be stated that the cross IGBTs gate driver open circuit fault in the inverter are more stringent and increase the vibration of the motor, faults caused by cross diodes open in the rectifier circuit tends to reduce the DC input voltage to the inverter and decelerate the load. Rectifier diodes, IGBT inverter switches, short circuit faults raise the temperature and can mutilate the diodes, IGBTs, and motor windings. Evaluation of the system parameters such as stator currents, temperature, speed in real-time plays an important role in the fault diagnosis. Performance evaluation scores such as the F1 score and accuracy of both the machine learning algorithms are evaluated. MLP-NN and multiclass SVM can be used for fault diagnosis, and the most severe incipient IGBT faults can be precisely diagnosed. The multiclass SVM's computational time is less compared to MLP-NN. Hence SVM can be preferred over MLP-NN as per the experimental results. A User-friendly web tool can be designed to identify the fault location to aid the operator from the classified results. The work can be extended to find the mechanical faults such as broken rotor bar faults, SLG fault at the motor input terminal, and simultaneous occurrence of electrical incipient mechanical faults like cross IGBTs open and broken rotor bars in the system. The data extracted from the real-time monitoring of Variable Frequency Drives are displayed to the operator and can be used for the analysis of various types of faults using advanced signal processing techniques.

\section{REFERENCES}

1. Shu-Ying Li, Lei Xue, “Motor's Early Fault Diagnosis Based on Support Vector Machine,” AMIMA 2018 IOP Publishing, IOP Conf. Series: Materials Science and Engineering 382 (2018) 032047, pp 1-4, 2018 doi:10.1088/1757-899X/382/3/032047

2. Khireddine, M.S. \& Slimane, N. \& Abdessemed, Yassine \& Makhloufi, M.T, "Fault detection and diagnosis in induction motor using artificial intelligence technique," MATEC Web of Conferences, vol 16, pp-1-5, 2014

Published By:

Blue Eyes Intelligence Engineering and Sciences Publication (BEIESP)

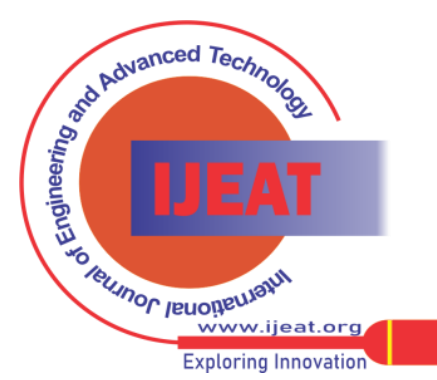


3. Furqan Asghar, Muhammad Talha, and Sung Ho Kim, "Comparative Study of Three Fault Diagnostic Methods for Three Phase Inverter with Induction Motor," International Journal of Fuzzy Logic and Intelligent Systems, Vol. 17, No. 4, pp. 245-256, December 2017, DOI: 10.5391/IJFIS.2017.17.4.245.

4. Sebah, M. I., \& Osama, M, "Fault diagnostics in an inverter feeding an induction motor using fuzzy logic," Journal of Electrical Systems and Information Technology, Vol 4(1), pp. 10-17, May 2017.

5. Ibrahim, S. O. et al. "Implementation of a fuzzy modeling system for faults detection and diagnosis in three phase induction motor drive system." Journal of Electrical Systems and Information Technology, vol. 2, pp-27-46, 2015.

6. Gomathy, Dr \& S, Selvaperumal, "Fault Detection and Classification with Optimization Techniques for a Three-Phase Single-Inverter Circuit" Journal of Power Electronics, Vol 16, pp 1097-1109, May 2016.

7. H. Yang, J. Zhao and F. Wu, "Current similarity based fault diagnosis for induction motor drives with discrete wavelet transform," 2016 Prognostics and System Health Management Conference (PHM-Chengdu), Chengdu, 2016, pp. 1-6, DOI: 10.1109/PHM.2016.7819841.

8. Dong-Eok Kim and Dong-Choon Lee, "Fault diagnosis of three-phase PWM inverters using wavelet and SVM," IEEE International Symposium on Industrial Electronics, pp. 329-334, 2008, DOI: 10.1109/ISIE.2008.4676998.

9. Wei, Li, Xu, and Huang, "A Review of Early Fault Diagnosis Approaches and Their Applications in Rotating Machinery," Entropy, vol. 21, no. 4, p.409, Apr. 2019.

10. H. Zhao, W. Deng, R. Yao, M. Sun, Y. Luo, and C. Dong, "Study on a novel fault diagnosis method based on integrating EMD, fuzzy entropy, improved PSO and SVM," Journal of Vibroengineering, vol. 19, no. 4, pp. 2562-2577, Jun. 2017.

11. R. Jyothi, R. Jayapal and K. U. Rao, "Severity and impact of faults on current harmonics in inverter-fed AC drives," 2016 IEEE Innovative Smart Grid Technologies - Asia (ISGT-Asia), Melbourne, VIC, 2016, pp. 401-405, DOI: 10.1109/ISGT-Asia.2016.7796419.

12. R. Jyothi et al., "Automatic Fault Diagnosis System for Voltage Source Inverter Driven Induction Motor, "2019 3rd International Conference on Recent Developments in Control, Automation \& Power Engineering (RDCAPE), NOIDA, India, pp. 477-481, 2019.

13. Jyothi R., Sumitgupta, Rao K.U., Jayapal R. (2021) IoT Application for Real-Time Condition Monitoring of Voltage Source Inverter Driven Induction Motor. In: Raj J.S., Iliyasu A.M., Bestak R., Baig Z.A. (eds) Innovative Data Communication Technologies and Application. Lecture Notes on Data Engineering and Communications Technologies, vol 59. Springer, Singapore. https://doi.org/10.1007/978-981-15-9651-3_8

14. Shalini Vasishta, KR Rekha, "A Survey: Space Vector PWM (SVPWM) in $3 \varphi$ Voltage Source Inverter (VSI)", International Journal of Electrical and Computer Engineering (IJECE), Vol. 8, No.1, pp. 11-18, February 2018.

15. Rekha SN, P Aruna Jeyanthy, D Devaraj, "Relevance vector machine based fault classification in wind energy conversion system,' International Journal of Electrical and Computer Engineering (IJECE), Vol. 9, No.3, pp. 1506-1513, June 2019.

16. Holla Tejas \& Rao U \& Jayapal R. \& Jyothi. R, "Machine learning-based multi class fault diagnosis tool for voltage source inverter driven induction motor," International Journal of Power Electronics and Drive Systems (IJPEDS). Pp 1205-1215. Vol 12, issue 2 10.11591/ijpeds.v12.i2.pp1205-1215.

\section{AUTHORS PROFILE}

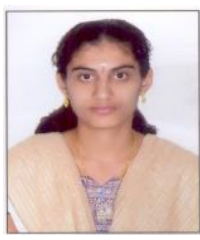

Jyothi R, received B.E in Electrical and Electronics Engineering and M.Tech in Power Electronics From Visvesvaraya Technological University in the year 2009 and 2013, respectively. She is currently pursuing a Ph.D. at Visvesvaraya Technological University. She has 8 years of teaching experience and currently working as an Assistant Professor in the Department of Electrical and Electronics Engineering, RV College of Engineering, Bangalore. She has guided projects in the area of Power Electronics and Machine Learning. Her research interests include Power Electronics, Drives, and Fault diagnosis using Artificial Intelligence, Renewable Energy Systems, and Electrical Machines. She has authored six articles in the area of Power Electronics and Drives.

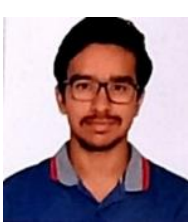

Tejas Holla, has completed B.E in Electrical and Electronics Engineering at RV College of Engineering, Bangalore. His areas of interest include Power Electronics and Drives, Machine Learning, Internet of Things and Embedded Systems, FPGA. He has also participated in the National Level Formula Bharat Electric vehicle engineering design Competition.

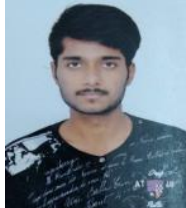

Umesh NS, has Completed B.E in Electrical and Electronics Engineering at RV College of Engineering, Bangalore. His areas of interest include Power Electronics and Drives, Machine Learning, Internet of Things Electrical Machines, Power Electronics, VLSI, and Embedded systems.

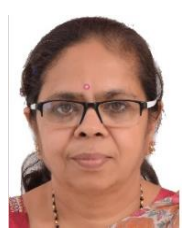

K Uma Rao, obtained her B.E in Electrical Engineering and M.E in Power systems from University Visvesvaraya College of Engineering, Bangalore, in 1984 and 1987, respectively. She received her Ph.D. from the Indian Institute of Science, Bangalore, in 1997. She has 32 years of teaching experience and currently working as a Professor in the Department of Electrical and Electronics Engineering, R.V. College of Engineering, Bangalore. Her research interests include FACTS, Custom Power, Power Quality, renewable energy, and technical education. Dr. K Uma Rao has published 12 technical books and more than 170 technical publications in national and international journals and conferences. She had also received 11 awards of excellence from various technical societies.

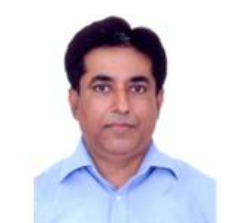

Jayapal R, obtained his B.E in Electrical Engineering and M.E in Power systems from University Visvesvaraya College of Engineering, Bangalore, respectively. He received his Ph.D. from Vivesvaraya Technological University in 2012. He has 29 years of teaching experience and currently working as a Principal at RV Institute of Technology and Management, Bangalore. His areas of interest include Robust control systems, loop shaping techniques, real-time simulators, and robust power system stabilizers. He has authored 20 articles in the areas of Power Systems and Power Electronics.

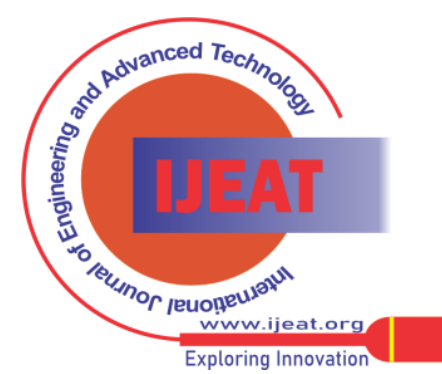

